\title{
Urban planning approaches to the development of social infrastructure, considering the behavioral preferences of the population (Moscow, Russia)
}

\author{
Yulia Strashnova ${ }^{1, *}$, Lyudmila Strashnova ${ }^{1}$, and Irina Makarova ${ }^{1}$ \\ ${ }^{1}$ State Autonomous Institution Research and Design Institute of the General Plan of the City of \\ Moscow, 2/14, 2-Ya Brestskaya Ulitsa, 125047, Moscow, Russia
}

\begin{abstract}
Sociological studies in urban planning are increasingly being used in planning the placement of facilities across the city, including facilities in the service sector. When conducting a sociological study, the following methods were used: population survey (using online questionnaire), field survey (collection of information about the territory, population, its movements with cultural and domestic purposes, prevailing development, condition of facilities), analysis and generalization of survey results, comparison with data of the official statistics. The results of the study are: the main areas for the development of the social infrastructure of the city and a model of integrated functional and spatial organization of facilities developed taking into account modern behavioral preferences of various socio-demographic groups of the population. On the territory of the city of Moscow (in residential quarters, groups of residential quarters, groups of districts, administrative districts), a new type of facilities is proposed for placement - a multifunctional public complex (MPC) of socio-cultural purpose. The proposed functional composition of MPCs is formed taking into account a survey of the main consumers of services socio-demographic groups of the population and their behavioral preferences. The main peculiarity of MPCs is the combination of cultural, sports, and additional education facilities that are currently insufficiently present in the urban environment.
\end{abstract}

\section{Introduction}

The paper is devoted to urban planning techniques for placing social infrastructure in urban areas using the results of a sociological study. The initial data for the study were official statistics on the current number and structure of consumer groups in the city of Moscow, on the location of social infrastructure in the city; population survey data on satisfaction with the development of social infrastructure in the area of residence (provision with facilities, their spatial availability); materials of approved documentation for the planning of the territory, including urban development plans for land plots.

\footnotetext{
*Corresponding author: imakarova@genplanmos.ru
} 
Sociological studies in the field of urban development have been carried out by domestic and foreign experts for the purposes of "participatory design" ("architecture of participation" or "architecture of local communities") from the middle of the last century (1960s). In the 1960s, studies were conducted by American experts (Sanoff G., Christopher A., John Chris, Jones G.S. - Design Methods Group - DMG, USA). In 1969, they formed the Environmental Design Research Association (EDRA), an international organization that conducts research in the field of architecture, urban planning and design using methods of psychology, sociology and other fields (1). In the 2000s, the work of foreign researchers was devoted to the problems of public involvement in the transformation of the urban environment, the mechanisms of interaction between residents and authorities (2). The current trends of changes in consumer behavior of the population were studied (3).

In our country in the Soviet period, sociological research in urban planning was carried out by: Kogan L.B., Dridze T.M., Glazychev V.L.

In the 1990s, most of the work of domestic economists and sociologists was devoted to the problems of public participation in the process of strategic planning of the socioeconomic development of the territory of municipalities. It was noted that "when developing strategic planning documents and urban planning documents, in addition to the points of view of local governments and the business community, the opinion of the population must be taken into account". The Institute for Urban Economics Foundation developed a Model for public participation in the strategic planning process $(4 ; 5)$. In the 2000s, an important place for socio-urban research was given to the works of M.G. Barkhin, Z.I. Ivanova, T.N. Golomazova, E. Vlaskina: the study of lifestyle, population habits in connection with the increasing scale of housing, cultural and social construction, the needs of residents of various types of cities $(5 ; 6 ; 7 ; 8)$. The authors noted the need for sociological surveys of the population to assess urban-planning decisions and the effectiveness of the municipal authorities in the formation of a quality living environment: "no decision can be made without a preliminary study of public opinion, since it is about citizens' well-being and their subjective satisfaction with their life, the surrounding space" (6). "... comprehensive sociological research helps to involve different sectors of the population in the process of managing the development of the territory and to take their opinions into account in a timely manner. Nobody knows the strengths and weaknesses of their settlement, its problems and development opportunities better than the residents themselves living in this territory" (7). The works of the famous sociologist Vakhstein V. are devoted to the problems of microsociology, "behavioral urbanism". The author studies the behavior of the population in urban space, its perception of urban changes (8).

An important result of the study of the behavioral preferences of the population regarding the use of the social infrastructure of Moscow was the proposal to create multifunctional social complexes for socio-cultural purposes. It should be noted that multifunctional buildings appeared in the Moscow city development in the late 1990s early 2000s and are currently one of the promising types of facilities for investors and residents of the city. Mostly they combine residential, commercial and administrative (office) functions. In 2014, OJSC "TsNIIEP of residential and public buildings" (TsNIIEP of housing) developed a set of rules (SP 160.1325800.2014 "Multifunctional buildings and complexes. Design rules", approved by Order of the Ministry of Construction and Housing and Communal Services of the Russian Federation of 07.08.2014 N 440/pr.). According to this document, buildings are multifunctional if they "include two or more functional planning components that are interconnected with each other using planning techniques".

Multifunctional complexes, their advantages and negative aspects are considered in the works of architects, economists, specialists working in the field of construction and real estate. So, the architect Dubynin N.V. in the article "Architecture of multifunctional buildings and new building systems" outlines the prospects and modern possibilities of 
designing and constructing multifunctional buildings and complexes based on the use of innovative developments in building science in the development of the regulatory and methodological base of architectural design and new constructive and technological solutions for building systems (9).

Ulinich N.A. characterized multifunctionality as an integral component of urban architecture. It is emphasized that the construction of multifunctional buildings is "caused by the lack of free land, coupled with the ever-increasing pace of life of citizens" (10). Nadyrova D.A. studied the features of the formation of the architecture of estate leisure clubs in Kazan. The facilities were studied as multifunctional "complexes - prototypes of modern cultural and entertainment clubs and palaces of culture" (11). The work of A. Devlikamova presents an analysis of the space-planning evolution of multifunctional shopping complexes over a long retrospective period (from the 19th century to the present). The author noted that "the construction of multifunctional buildings has acquired the greatest importance for the full development of the urban environment ... in the largest cities of Russia", while "low-income specialized facilities have exhausted their capabilities in the modern city" (12). Mikhailova V. emphasized the important economic advantage of multifunctional complexes: "the combination of a mandatory socially significant function for the city and more profitable functions makes it possible to compromise between the burdens from the city and the commercial effectiveness of the project" (13). The article "Multifunctional complexes today: a problem, necessity or inevitability" outlines the main effects obtained by the investor-builder, the city and its residents from the creation of multifunctional complexes, including the efficient use of land, saving resources, reducing the cost of creating facilities due to their scale, the possibility of re-profiling the premises, high investment attractiveness of the project because of the reduction of risks due to diversification of investments (investments in various types of real estate) and others (14).

The novelty of the results of the study in question is to justify the feasibility of creating multifunctional social complexes for socio-cultural purposes, combining sports, recreational, leisure, educational functions, in contrast to the existing shopping, administrative, and hotel complexes.

\section{Materials and methods}

The study was carried out using the following methods: historical and logistic, functional and structural analysis, quantitative and qualitative analysis of primary and secondary sociological and statistical information, including observation, questionnaires (using the Internet), expert survey, statistical data processing using the SPSS software package, analytical generalization, interpretation and visualization of the obtained empirical materials.

\section{Results}

As a result of the sociological study by the State Autonomous Institution Research and Design Institute of the General Plan of the City of Moscow with a survey of the population of Moscow, the peculiarities of behavioral preferences of the population regarding the use of social infrastructure facilities were identified, the main areas of development and the model of the functional and spatial organization of these facilities in the city were specified.

Features of the behavioral preferences of the population include:

- changes in lifestyle, ways of spending free time: there is a tendency to increase the demand for leisure services (75\% go out for walks, 57\% meet friends, $56 \%$ increase their cultural level); 
- high level of use of information technology - Internet services in the field of trade, catering, education, culture;

- increasing demand for facilities in the service sector: culture, sports, additional education, social and psychological support;

- the growing need of the population to saturate the living environment with facilities of social infrastructure with a further increase in the density of social functions in the residential areas;

- unmet need for additional educational institutions in the residential areas $(60 \%$ of respondents who have children from the total number of respondents): $54 \%$ - pools, $33 \%$ ice rinks, 33\% - places for walk;

- relevance of the following types of facilities:

- in the field of education - centers for the additional education of children and adolescents (carpentry, auto-making, radio engineering, etc.); consultation centers for professional retraining; educational centers at museums and organizations;

- in the field of culture and leisure - clubs of intellectual games and sports; creative workshops; facilities for meetings and gatherings of local residents;

- in the field of social protection - centers of social adaptation; "anti-stress" centers; "kindergartens" for single elderly people; social canteens (for senior citizens, veterans);

- in the field of trade and consumer services - mobile distribution centers for online orders, restaurants, coffee shops, healthy food stores, which is associated with taking care of one's health and well-being, leisure - a cafe for communication and meetings.

Analysis and accounting of modern trends in the behavioral preferences of the population in the service sector allows formulating the main directions of development of social infrastructure and developing proposals for the formation of relevant types of facilities that enhance the use of the territory.

The main areas of the development of social infrastructure, taking into account the characteristics of consumer demand, include:

- intensification of the use of territorial resources of the city for the development of social functions, taking into account the creation of multifunctional public complexes (MPC), the use of the first floors of residential and non-residential buildings, exploited roofs, underground spaces of open public territories;

- effective use of the existing fund of social facilities, increase in hours of work;

- construction of sports and recreational, cultural and educational facilities, psychological support institutions while reducing the volume of new construction of trade facilities; increasing the diversity of social infrastructure facilities, including specialized facilities for children and elderly people, the active introduction of promising new types of facilities;

- improving the mechanism for concluding investment contracts for the construction of multifunctional public complexes with a functional structure that takes into account the interests of residents of a particular territory of the city.

The main areas of the development of social infrastructure made it possible to adjust the model of the integrated functional and spatial organization of social infrastructure facilities across the city, including the formation of facilities of regional and city significance at the regional level of service. The indicated facilities differ in terms of spatial availability (pedestrian, transport), functional purpose, elements of the planning structure (residential quarter, group of residential quarters, group of districts, administrative district, Fig. 1). The facilities of social infrastructure located on the territory of the residential quarter, groups of residential quarters are focused primarily on servicing children and people with limited mobility, on the territory of groups of districts - on servicing mainly mobile groups of the working population, on the territory of the administrative district - on servicing all groups of the daytime population (Fig. 1). 
To ensure the integrated development of public functions, the recommended spaceplanning techniques for placing social infrastructure in urban areas are summarized. They include the use of the ground floors of residential and non-residential buildings, built-in annexed premises, underground space of public and business buildings, exploited roofs of residential and public buildings, open and landscaped public spaces of the city (Fig. 2). The use of different urban planning techniques for placing social infrastructure in urban areas, namely in MPC, freestanding monofunctional buildings, ground floors of residential buildings, and built-in and attached buildings of residential and public buildings, will increase the variety and volume of services by $15 \%$ while reducing new construction by $15 \%$ and territory consumption by $18 \%$.

A combination of several functions at one site can be an effective technique for compiling social functions, which ensures the intensification of the use of the city's territorial resources.

\section{A MODEL OF THE FUNCTIONAL AND SPATIAL ORGANIZATION OF SOCIAL INFRASTRUCTURE FACILITIES IN} THE CITY

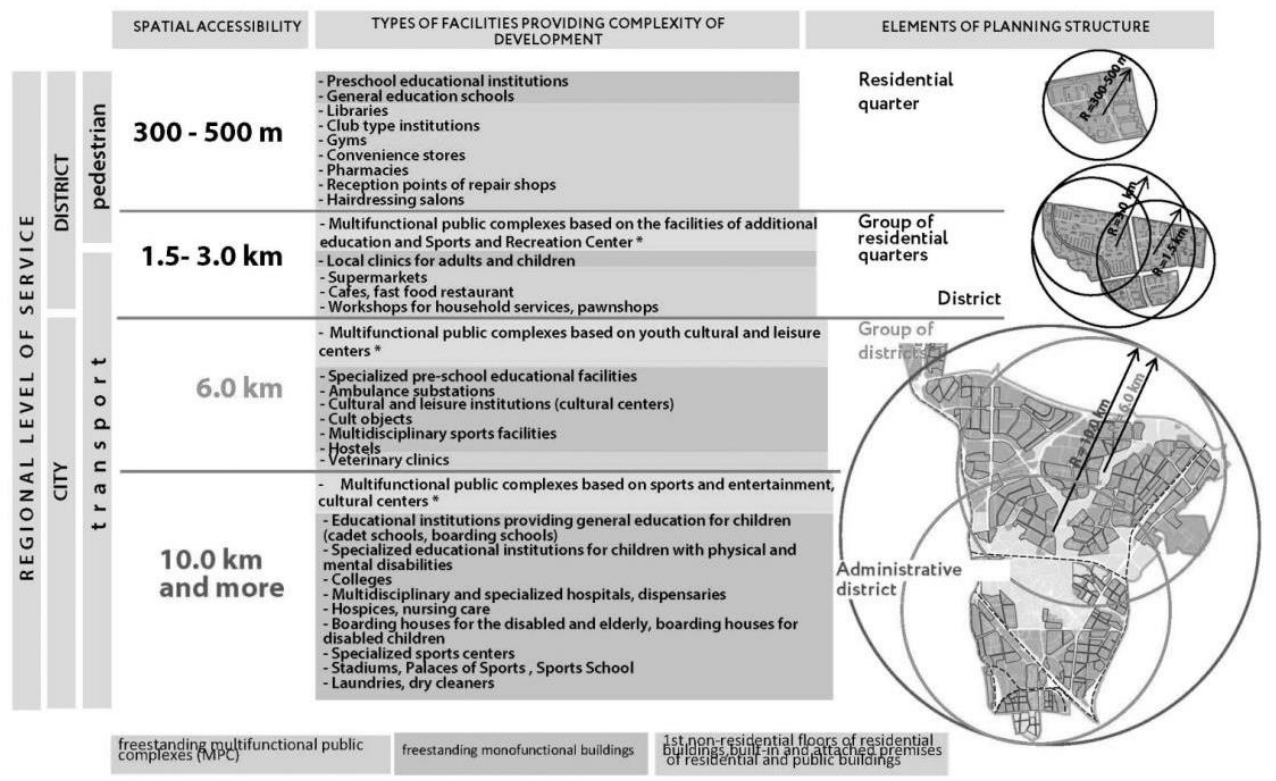

Fig. 1. A model of the functional and spatial organization of social infrastructure facilities in the city. 


\section{URBAN PLANNING TECHNIQUES FOR PLACING FACILITIES IN URBAN AREAS}

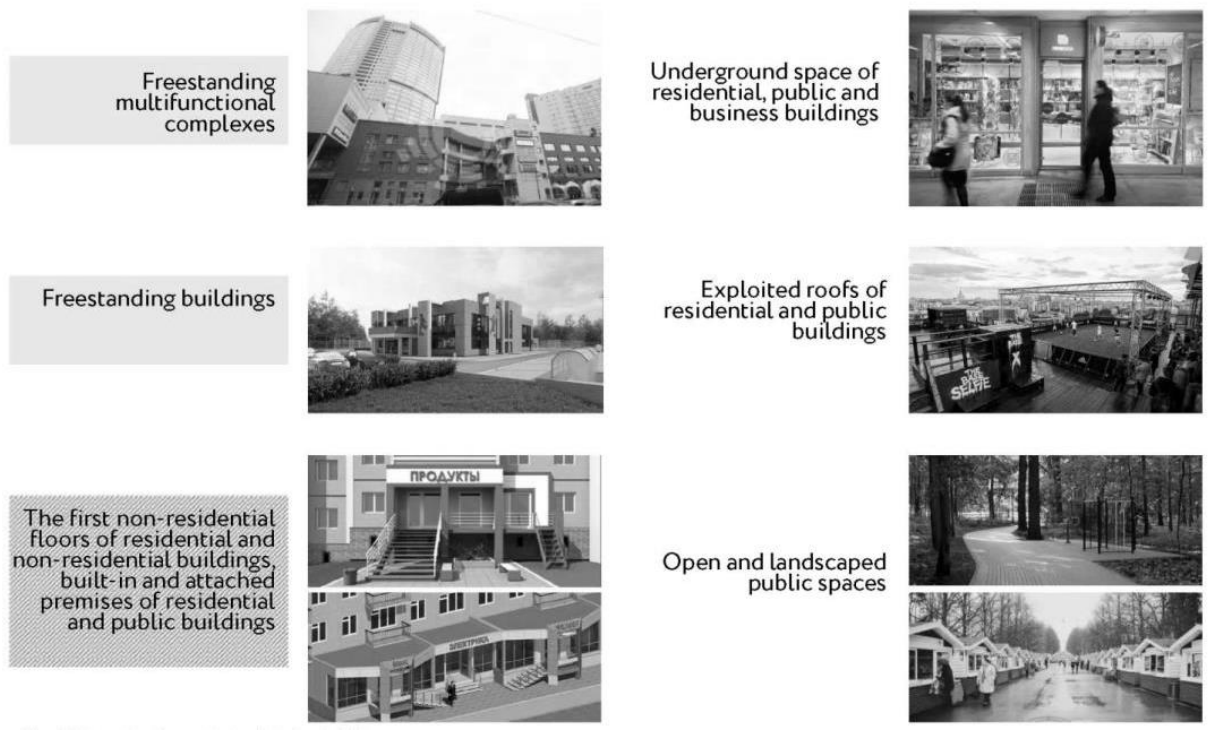

Fig. 2. Urban planning methods of placing facilities.

The main peculiarity of MPC is the combination of cultural, sports, and additional education facilities that are currently insufficiently present in the urban environment. The creation of socially-oriented multifunctional complexes meets the modern needs of the population, identified by the results of a sociological survey of residents about satisfaction with the development of social infrastructure. The advantages of the new form of combining functions in the MPC are:

- predominance of social services (sports, educational, cultural) over the trade, administrative and business components;

- orientation of the MPC to a specific set of users: the MPC of the first level is close to the consumer, provides a kilometer radius of spatial accessibility, is intended primarily for everyday visits by groups of people with limited mobility - children, elderly people living in the adjacent territory. The MPC of the second level provides services within a radius of 3 $\mathrm{km}$, is primarily focused on adolescents and youth with a visit 1-2 times a week. The MPC of the third level is designed for a service radius of more than $5 \mathrm{~km}$, involves the use of all groups of the population 1-2 times a month;

- MPC of the first and second levels can be integrated into residential development;

- presence of the MPC increases the prestige of the residential area, its investment performance, since it responds to the needs of population groups in unique services, for example, rare sports, relevant types of extracurricular education, social protection institutions - rest homes for single elderly people with a day stay and others;

- integrated functional composition of the MPC provides more employment opportunities for highly qualified specialists in the field of humanities and technical sciences near the habitat.

It is proposed to place multifunctional public complexes of social and cultural services for the population:

- on the territory of groups of residential quarters, groups of residential areas and administrative districts (Fig.3;4;5);

- on the basis of additional education facilities and fitness centers (area of 0.7-1.2 hectares, the total area of the complex is 10-20 thousand square meters; territorial 
accessibility of 1.5-3 km; main facilities of the MPC are: music, art school; center for the additional education of children and adolescents; film, vocals studio; "anti-stress" center; club of intellectual games and sports, etc.)

- on the basis of the youth cultural and leisure center (the area of 1.5-2.0 hectares, the total area of the complex - 20-50 thousand square meters; territorial accessibility of 3-6 km; the main facilities: a cultural center; theatre stage for offsite performances; multi-screen cinema; exhibition; interactive museum; club rooms; creative workshops and thematic workshops, etc.);

- on the basis of a sports, entertainment and cultural center (the area of 2.5-10.0 hectares, the total area of the complex - 50-200 thousand square meters; territorial accessibility of $10 \mathrm{~km}$ or more; main facilities: a stadium for sports entertainment events; ice arena; water park, pool; climbing wall; training rooms, etc.).

Additional investment facilities for accommodation in all types of multifunctional public complexes are commercial, administrative, public and business premises, as well as public catering facilities.

The proposed functional composition of MPCs is formed taking into account the main consumers of services - socio-demographic groups of the population and their revealed behavioral preferences (Fig. 6):

- preschool children (3-6 years old) - entry into society, obtaining primary learning skills as a result of visiting preschool institutions, sections and circles of additional education, children's theatres, parks; use of mobile devices and computer games;

- children and adolescents of school age (7-15 years) - active assimilation of knowledge from all possible sources, including from the virtual world, games, the period of wakefulness is accompanied by a computer almost $90 \%$ of the time, do not imagine themselves without computers, mobile phones and the Internet; easily motivated by exciting projects and quickly achievable goals;

- youth (16-24 years) - health care activities; interest in quality of service; changing priorities - reducing the time for household chores (catering, cleaning) in favor of a more interesting, productive, creative activity; continuous education and development, selfemployment (freelance); have high expectations and inquiries; need for active sports, including extreme ones (purchase of tourist and sports equipment); visits to Internet cafes, interest clubs, leisure and entertainment centers;

\section{COMPOSITION OF A MULTIFUNCTIONAL PUBLIC COMPLEX (MPC) based on facilities of additional education and sports and recreation center district significance}
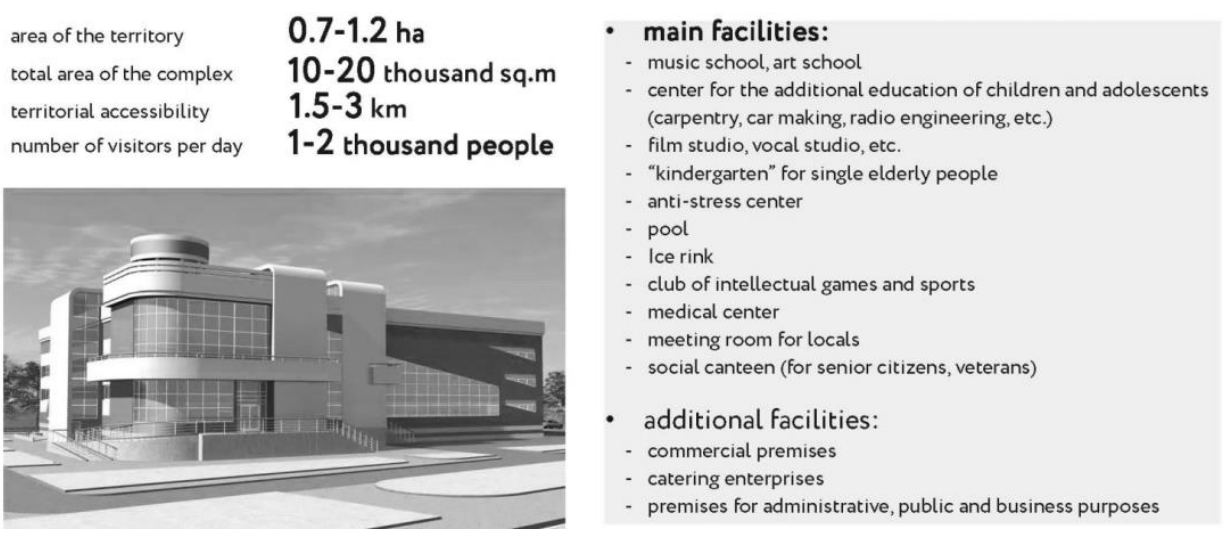

Fig. 3. A multifunctional public complex based on facilities of additional education and sports and recreation center. 


\section{COMPOSITION OF A MULTIFUNCTIONAL PUBLIC COMPLEX(MPC) based on the youth cultural and leisure center interdistrict significance}

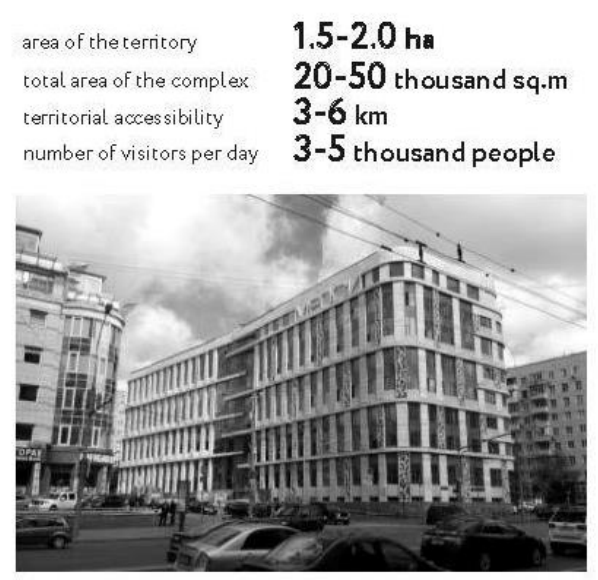

- main facilities:

- house of culture

theatre stage for offsite performances

- multi-screen cinema

- exhibition

- interactive museum

- club rooms

- training counselling center

research and development innovative laboratories

- creative workshop

thematic workshops

- club of intellectual games and sports

center of rhythmic gymnastics, weightlifting, wrestling and boxing, etc.

- center for social adaptation

mabile distribution center of online orders

- additional facilities:

- commercial premises

catering enterprises

- premises for administrative, public and business purposes

Fig. 4. A multifunctional public complex based on the youth cultural and leisure center.

\section{COMPOSITION OF A MULTIFUNCTIONAL PUBLIC COMPLEX (MPC) based on the sports, entertainment and cultural center city significance}

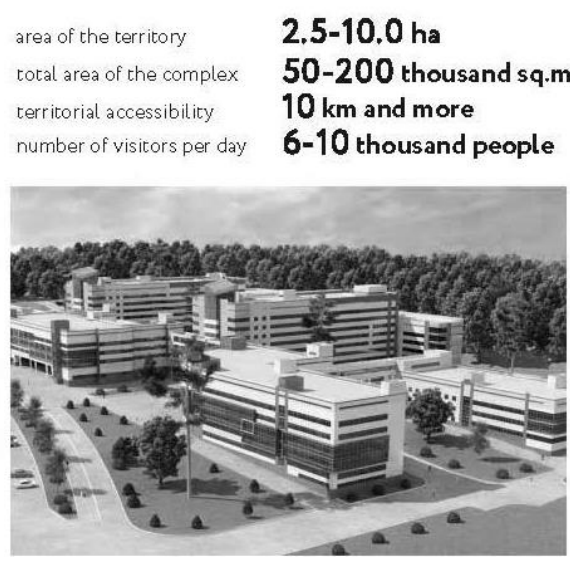

- main facilities:

- stadium for sports and entertainment events - ice arena

- water park, pool (for synchronized swimming) climbing wall go-kart center rollerdrome gyms cinema exhibition space conference rooms recreational complex with the function of diagnosis and prevention

- additional facilities: commercial premises catering enterprises

premises for administrative, public and business purposes

Fig. 5. A multifunctional public complex based on the sports, entertainment and cultural center. 


\section{POPULATION GROUPS. \\ THE MAIN CONSUMERS OF SERVICES}

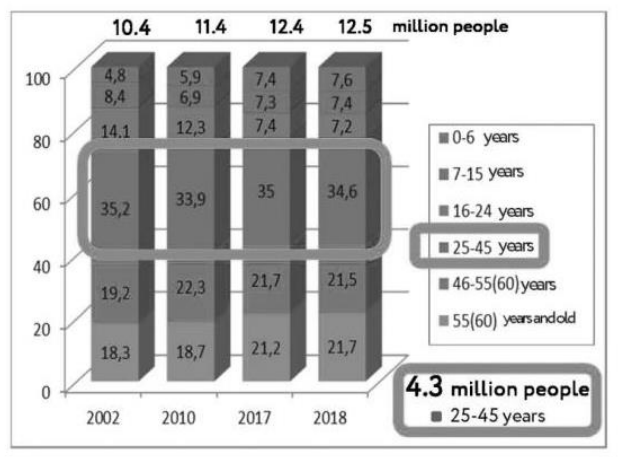

The main consumers of services - drivers of innovation (group 25-45 years old) - present modern requirements for the service infrastructure and are potential consumers of innovative services, while maintaining their preferences when moving to the next age ranges
THEORY OF GENERATIONS. DIFFERENCES IN CONSUMER
PREFERENCES

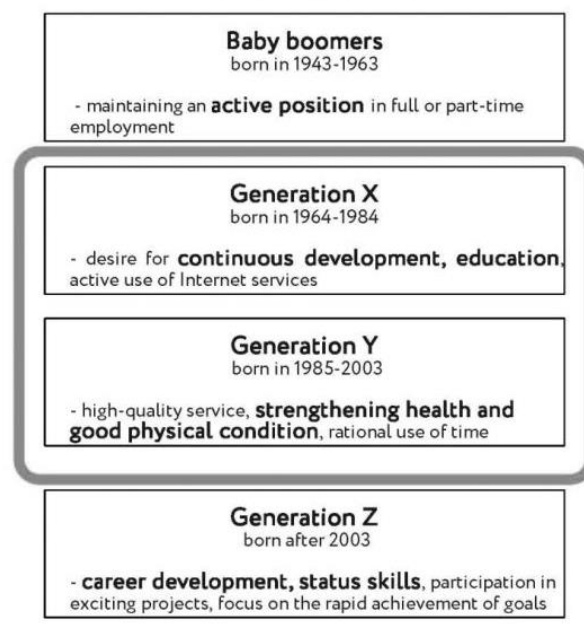

- Actual foreign trends in consumer behavior in 2016-2017, (source : http://prclub.spb.ru/2017/09/02/consumertrends/)

Fig. 6. Socio-demographic groups of the population and their revealed behavioral preferences.

- the most active group of the working-age population (25-45 years) - the desire to reduce time for purchases, household services, etc., the active consumption of online services in the field of food, education, culture, social protection, consumer services, trade; constant use of email, social networks, smartphones, mobile applications; purchase of goods on credit; using the services of housekeepers and nannies; use of the services of beauty and spa salons, classes in fitness centers and sports clubs;

- an active group of the working-age population (46-60 years) - rational consumption the choice of reliable and high-quality goods at reasonable prices; deep interest in a healthy lifestyle, effective activity, ecological nutrition; identification of new areas of personal interest;

- a less active group of the population older than working age over 60 years old - a deep need for social activities, the need for relatives and society, a desire to share professional knowledge and experience, care about their health; make online purchases less regularly; mostly prefer to shop directly at the store; hobby - tourism.

The main mass of consumers is the working population (including students), 25-45 years old - "active and functional" youth who know what they want and have enough money to realize their aspirations. It is this group that determines the modern requirements for the service infrastructure, is the so-called "driver of innovation" and at the same time a potential consumer of the service sector in the future, which means that the current trends in consumer preferences will continue in the dynamics when this group moves to the following age range.

Changes in consumer behavior are caused by increased life expectancy and the division of the population into age groups with different value systems and groups of motivating factors. The current demographic changes make generation theory one of the main tools used by marketers (theory developed by W. Strauss and N. Hove, describing repetitive generational cycles and related patterns of behavior in the US history (Generations, 1991; The Fourth Turning, 1997)).

The main differences in consumer preferences of representatives of different generations are: Baby boomers (born in 1943-1963) - retaining an active position with full 
or partial employment; Generation X (born in 1964-1984) - with a characteristic desire for continuous development, training, active use of Internet services; Generation Y (born in 1985-2003) - preferring high-quality service, strengthening health and good physical condition, rational use of time; Generation Z (born after 2003) - aimed at developing a career, status skills, participating in exciting projects, focusing on quickly achieving goals.

\section{Discussion and conclusion}

A sociological survey of residents of certain districts of Moscow on satisfaction with the development of social infrastructure showed that the most popular facilities now are: centers for the additional education of children and adolescents, counseling centers for professional retraining; educational centers at museums and organizations (in the field of education); clubs for intellectual games and sports, creative workshops, rooms for meetings and gatherings of residents in the field of culture and leisure; centers of social adaptation; "anti-stress" centers; "kindergartens" for single elderly people; social canteens for senior citizens, veterans (in the field of social protection); mobile centers for the distribution of Internet orders, restaurants, coffee houses, health food stores, leisure - cafes for communication and meetings (in the field of trade and consumer services).

As a result of a sociological study, the main areas of the development of social infrastructure are formulated, including the intensification of the use of the city's territorial resources for the development of social functions by creating a new type of facilities multifunctional public complexes (MPC), which allow combining functions with the predominance of social services (sports, recreational, educational, cultural) over trade, administrative and business functions. The indicated facilities differ in terms of spatial availability (pedestrian, transport), functional purpose, elements of the planning structure (residential quarter, group of residential quarters, group of districts, administrative district). The social infrastructure facilities that are proposed for placement on the territory of a residential quarter, groups of residential quarters are oriented, first of all, to the daily services of children and people with limited mobility (located within a radius of kilometer accessibility - MPC of the first level). MPCs located on the territory of groups of districts are intended for periodic servicing of mainly mobile groups of the working population 1-2 times a week (within a radius of spatial availability of up to $3 \mathrm{~km}$ ) - MPCs of the second level. On the territory of the administrative district, it is proposed to place MPCs (within a service radius of more than $5 \mathrm{~km}$ ) focused on providing services to all groups of the daytime population, intended for visits 1-2 times a month, - MPC of the third level.

Recommended space-planning techniques for placing social infrastructure in urban areas include the use of ground floors of residential and non-residential buildings, built-in attached buildings, underground space of public and business buildings, exploited roofs of residential and public buildings, open and landscaped public spaces of the city.

\section{References}

1. H. Sanoff, Towards Architecture Concerned by Man. About designing people, with people and for people, http: //archvestnik.ru/node/2124

2. G. Sanoff, Methods of complicity of territorial communities in design and planning (2000)

3. R. Graz, City in America: Residents and Authorities (Development Society native culture, Moscow, 2008)

4. E. Ponomareva Current foreign trends in consumer behavior in 2016-2017, PR Club Business Daily, http://prclub.spb.ru/2017/09/02/consumertrends 
5. G.Yu. Vetrov, V.V. Ladygin Public participation in the strategic planning process. Municipal strategies: ten years later (International Center for Social and Economic Research "Leontief Center", St. Petersburg, 2011)

6. M.G. Barkhin, Sociological studies of the city https://tatlin.ru/articles/sociologicheskie_issledovaniya_goroda

7. Z.I. Ivanova, T.N. Golomazova, Stroitelstvo: nauka i obrazovanie 1 (2014) http://www.nso-iournal.ru

8. E. Vlaskina, Practice of municipal management 3 (2015)

9. V. Wachstein, Urban studies in sociology. Interview, https://www.msses.ru/about/news/4324/

10. N.V. Dubynin, Housing construction 5, 63-66 (2014)

11. N.A. Ulinich, Architecture and Modern Information Technologies 1(42), 150-162 (2018) http://marhi.ru/AMIT/2018/1kvart18/10_ulinich/index.php

12. D.A. Nadyrova, News of Kazan State University of Architecture and Civil Engineering (2017)

13. A.S. Devlikamova, Young scientist 7, 1104-1109 https://moluch.ru/archive/87/16814/

14. V. Mikhailova, Multifunctional complexes - combination of incompatible, https://www.officevmoskve.ru/articles/mfk/

15. Multifunctional complexes today: a problem, necessity or inevitability, http://www.bacnet.ru/knowledge-base/articles/index.php?ELEMENT_ID=720 